\title{
microRNAs as Regulators of Adipogenic Differentiation of Mesenchymal Stem Cells
}

\author{
Dana Hamam, ${ }^{1,{ }^{*}}$ Dalia Ali, ${ }^{1, *}$ Moustapha Kassem, ${ }^{1,2}$ Abdullah Aldahmash, ${ }^{1,2}$ and Nehad M. Alajez ${ }^{1}$
}

microRNAs (miRNAs) constitute complex regulatory network, fine tuning the expression of a myriad of genes involved in different biological and physiological processes, including stem cell differentiation. Mesenchymal stem cells (MSCs) are multipotent stem cells present in the bone marrow stroma, and the stroma of many other tissues, and can give rise to a number of mesoderm-type cells including adipocytes and osteoblasts, which form medullary fat and bone tissues, respectively. The role of bone marrow fat in bone mass homeostasis is an area of intensive investigation with the aim of developing novel approaches for enhancing osteoblastic bone formation through inhibition of bone marrow fat formation. A number of recent studies have reported several miRNAs that enhance or inhibit adipogenic differentiation of MSCs and with potential use in microRNA-based therapy to regulate adipogenesis in the context of treating bone diseases and metabolic disorders. The current review focuses on miRNAs and their role in regulating adipogenic differentiation of MSCs.

\section{Introduction}

$\mathrm{R}$ ECENT YeARS HAVE WITNESSED immense interest in studying mesenchymal stem cells (MSCs) and harnessing their unique differentiation capabilities for tissue engineering and regenerative medicine applications. While there are a myriad of molecular mechanisms that regulate stem cell differentiation, a new class of epigenetic regulators "microRNAs" have emerged as key player during stem cell differentiation including MSC. The role of microRNAs (miRNAs) in regulating MSC differentiation are currently being unraveled using integrated, experimental, and bioinformatics approaches. Our understanding of miRNAs and how they regulate MSC differentiation will have significant impact on their therapeutic potential. In this review, we will provide an overview of MSC differentiation into adipocytes and an up-todate analysis of published data implicating miRNAs in regulating the adipogenic differentiation of MSCs.

\section{Adipocytic Differentiation of MSCs}

MSCs are described as adult progenitor multipotent stromal cells found and isolated from multiple tissues, including among others bone marrow [1], adipose tissue [2], umbilical cord [3], and skin [4]. MSCs have been shown to differentiate into several mesenchymal lineages including osteoblast, chondrocytes, and adipocytes to give rise to bone, cartilage, and adipose tissue, thus representing a possible use in cell therapy and regenerative medicine protocols $[1,5]$.

The process of adipogenesis includes two major phases; the determination phase and the maturation phase. During the phase of determination, multipotent MSCs become incapable of differentiation into other mesenchymal lineages as they commit only to adipocytic lineage [6]. At this point, both adipocyte-committed MSCs (preadipocytes) and their precursors have a similar morphological phenotype. Later on, and in the maturation phase, these preadipocytes are transformed into mature adipocytes, which take part in synthesizing and the transportation of lipid, secretion of adipocyte-specific proteins and possessing the machinery that is required for insulin sensitivity [6]. The process of adipogenesis revealed a mark shift in the pattern of gene expression observed in undifferentiated MSC compared to mature adipocyte, which promotes and terminates the phenotypic and molecular characteristics that identify mature adipocytes [7]. A complex and well organized signaling cascades appear to be involved in regulating adipogenesis, which includes the expression of several transcription factors such as peroxisome proliferator-activated receptor- $\gamma$ (PPAR $\gamma)$ and members of the CCAAT/ enhancer-binding family of proteins $(\mathrm{C} / \mathrm{EBPs}$ ) (reviewed in Rosen et al. [7]). Bone marrow adipocytes appear to play significant role in bone metabolism [8], therefore, better understanding of stromal adipocyte commitment and maturation and identifying the molecular mechanisms that regulate their

\footnotetext{
${ }^{1}$ Stem Cell Unit, Department of Anatomy, College of Medicine, King Saud University, Riyadh, Kingdom of Saudi Arabia.

${ }^{2}$ Molecular Endocrinology, KMEB, Department of Endocrinology, University of Southern Denmark, Odense, Denmark.

*These two authors contributed equally to this work.
}

(C) Dana Hamam et al. 2015; Published by Mary Ann Liebert, Inc. This Open Access article is distributed under the terms of the Creative Commons License Attribution-Non-Commercial Share Alike (<http://creativecommons.org/licenses/by-nc-sa/4.0/>). 
formation will assist in developing novel therapeutic modalities to regulate osteogenesis and hematopoiesis.

\section{microRNAs and Regulation of MSC Differentiation}

miRNAs are short single-stranded RNA sequences (usually 19-23 nucleotides), which are derived from $\sim 70$ nucleotide precursors, and play a critical role in the post-transcriptional regulation of gene expression in a broad range of biological systems varying from insects to humans [9-12], through controlling a wide range of physiological and developmental processes [13]. Changes in microRNAs have been associated with many human diseases such as cancer [14-16], myocardial infarction and cardiovascular diseases [17,18], diabetes, and obesity [19-21]. miRNAs have been identified to act in functional networks linked to several genes as potential targets; so far, an almost 2,578 miRNAs have been identified in human cells, which apparently can affect multiple physiological and biological functions, such as stem cell differentiation, neurogenesis, hematopoiesis, immune response, and skeletal and cardiac muscle development [2227]. While several reviews has covered the role of miRNAs in regulating osteoblastic differentiation of MSCs [28,29], the focus of this review is to highlight the regulation of adipogenic differentiation of MSCs by miRNAs.

\section{microRNAs and Regulation of Adipogenic Differentiation of MSCs}

A cascade of transcriptional events that occurs during adipocyte maturation, including the expression of PPAR $\gamma$ and CCAAT/enhancer-binding protein- $\alpha(\mathrm{C} / \mathrm{EBP} \alpha)$, which are key factors regulating a myriad of adipocyte-related enzymes and proteins involved in generating and sustaining adipocyte phenotype [30-32]. Furthermore, there are other factors that can directly or indirectly interact with $\operatorname{PPAR} \gamma$, such as adipocyte determination and differentiation-dependent factor 1 (ADD1/SREBP-c1), a homolog of sterol regulatory elementbinding proteins (SREBP), which was initially cloned as a basic helix-loop-helix (bHLH) protein involved in early adipogenesis, and another binding protein, a sterol response element (SRE) [33,34]. In addition, Krox20, Krüppel-like factors, and signal transducers and activators of transcription have all been shown to be tightly relevant to adipocyte differentiation [35-37]. All these transcription factors share a common characteristic as they regulate adipocyte differentiation by regulating the activity of PPAR $\gamma$ and C/EBP family. Adipocyte differentiation is regulated by the activity of various growth factors and hormones. Recent data suggested that miRNAs could be involved in human adipocyte maturation [38]. Tables 1 and 2 summarize the currently described microRNAs involved in adipocyte differentiation of MSCs derived from different sources.

\section{microRNAs targeting cell cycle and self-renewal-related genes}

miRNAs are able to indirectly regulate adipogenic differentiation of MSCs by targeting various genes that may be involved in balancing self-renewal and stem cell differentiation, as shown with miR-143, which was reported as the first miRNA to regulate adipogenesis [39]. Elevated levels of miR-143 were detected in differentiated white adipocytes and its inhibition resulted in reduced adipocytic differentiation. miR-143 was found to target extracellular signalregulated kinase 5 (ERK5), also known as mitogen-activated protein kinase 7 (MAPK7) gene, which is involved in promoting cell growth and proliferation in response to tyrosine kinase signaling, where its activation resulted in boosting adipocyte differentiation $[40,41]$. While the role of ERK5 in regulating adipocyte differentiation directly has not been confirmed, the authors suggested that it may play a role in balancing the proliferation and differentiation of adipocytes. Another member of ERK family was also studied as a target for miR-375 in 3T3-L1 cells [42]. The authors demonstrated that ERK1/2 pathway negatively regulate adipocyte differentiation, and suggested this reduction in adipogenesis is mediated through miR-375. Wang et al. found that all members of miR-17-92 cluster were significantly

Table 1. Mammalian microRnAs Involved in Adipogenesis in Bone Marrow-Derived Mesenchymal Stem Cells

\begin{tabular}{|c|c|c|c|c|}
\hline miRNA & Cell & Target gene $(s)$ & Related process & Reference \\
\hline miR-204 & $\begin{array}{l}\text { ST2 and C2C12 } \\
\text { mBMSCs } \\
\text { hMSCs }\end{array}$ & RUNX2 & $\uparrow$ Adipogenesis & [63] \\
\hline miR-637 & Bone marrow-derived MSCs & Osterix & $\uparrow$ Adipogenesis & [67] \\
\hline miR-320 & Bone marrow-derived MSCs & RUNX2 & $\uparrow$ Adipogenesis & [64] \\
\hline miR-378/378* & $\begin{array}{l}\text { Bone marrow-derived } \\
\text { ST2 cell line }\end{array}$ & $\begin{array}{l}\text { AGO2 } \\
\text { KLF15, FABP4, FAS, } \\
\text { SCD-1, and resistin }\end{array}$ & $\uparrow$ Adipogenesis & [88] \\
\hline $\begin{array}{l}\operatorname{miR}-8, \operatorname{miR}-200 c, \\
\quad-141,-200 b,-200 a,-429\end{array}$ & $\begin{array}{l}\text { Mouse ST2 marrow-derived } \\
\text { stromal cells (MSCs ST2) }\end{array}$ & $\begin{array}{l}\text { wntless (wls) } \\
\text { and CG32767 genes }\end{array}$ & $\uparrow$ Adipogenesis & [49] \\
\hline $\mathrm{miR}-199$, and $\mathrm{miR}-346$ & hMSCs from bone marrow & LIF & $\uparrow$ Adipogenesis & [55] \\
\hline $\operatorname{miR}-31$ & $\begin{array}{l}\text { Murine mesenchymal stem } \\
\text { cell line C3H10T1/2 (MSCs) }\end{array}$ & CEBPA & $\downarrow$ Adipogenesis & [78] \\
\hline $\operatorname{miR}-24$ & $\begin{array}{l}\text { Murine mesenchymal stem } \\
\text { cell line C3H10T1/2 (MSCs) }\end{array}$ & Unknown & $\uparrow$ Adipogenesis & [78] \\
\hline $\operatorname{miR}-335$ & Bone marrow-derived hMSCs & RUNX2 & $\downarrow$ Adipogenesis & [66] \\
\hline
\end{tabular}

hMSCs, human mesenchymal stem cells; mBMSCs, mouse bone marrow-derived MSCs; $\uparrow$, promote; $\downarrow$, inhibit. 
Table 2. Mammalian microRNAs Involved in Adipogenesis in Adipose-Derived Mesenchymal Stem Cells and Preadipocytes

\begin{tabular}{|c|c|c|c|c|}
\hline$m i R N A$ & Cell & Target gene(s) & Related process & Reference \\
\hline miR-17-92 & 3T3-L & $\mathrm{Rb} / \mathrm{p} 130$ & $\uparrow$ Adipogenesis & [43] \\
\hline $\operatorname{miR}-642 a-3 p$ & hAD-MSC & Unknown & $\uparrow$ Adipogenesis & [65] \\
\hline miR-30a and 30d & hAD-MSC & RUNX2 & $\uparrow$ Adipogenesis & [65] \\
\hline $\operatorname{miR}-21$ & hAD-MSC & TGF-B1 & $\uparrow$ Adipogenesis & [44] \\
\hline & 3Т3-11 & AP1 & $\uparrow$ Adipogenesis & [46] \\
\hline $\operatorname{miR}-30 \mathrm{c}$ & hAD-MSC and MEFs & $P A I-1$ and $A L K 2$ & $\uparrow$ Adipogenesis & [87] \\
\hline $\operatorname{miR}-210$ & 3T3-L1 & Tcf712 & $\uparrow$ Adipogenesis & [48] \\
\hline miR-143 & Human pre-ad & $\begin{array}{l}\text { ERK5 } \\
\text { MAPK7 }\end{array}$ & $\uparrow$ Adipogenesis & {$[39]$} \\
\hline $\operatorname{miR}-375$ & 3T3-L & ERK1/2 & $\uparrow$ Adipogenesis & [42] \\
\hline $\operatorname{miR}-27 b$ & hAD-MSC & $\operatorname{PPAR} \gamma$ and $\mathrm{C} / \mathrm{EBP} \alpha$ & $\downarrow$ Adipogenesis & [75] \\
\hline $\operatorname{miR}-27 a$ & $3 \mathrm{~T} 3-\mathrm{L}$ & $\operatorname{PPAR} \gamma$ & $\downarrow$ Adipogenesis & [76] \\
\hline $\operatorname{miR}-130$ & Human and mouse pre-ad & $\operatorname{PPAR} \gamma$ & $\downarrow$ Adipogenesis & [77] \\
\hline $\operatorname{miR}-138$ & hAD-MSCs & EID-1 & $\downarrow$ Adipogenesis & [79] \\
\hline $\operatorname{miR}-448$ & 3T3-L1 & KLF5 & $\downarrow$ Adipogenesis & {$[57]$} \\
\hline $\begin{array}{l}\mathrm{miR}-103 \\
\quad \text { and } \mathrm{miR}-107\end{array}$ & $\begin{array}{l}\text { Primary adipocytes and the stromalvascular } \\
\text { fraction from subcutaneous and visceral fat }\end{array}$ & CAV1 & $\downarrow$ Adipogenesis & {$[85]$} \\
\hline $\operatorname{miR}-146 b$ & 3T3-L1 & SIRT1 & $\uparrow$ Adipogenesis & [72] \\
\hline $\begin{array}{l}\operatorname{miR}-155 \\
\operatorname{miR}-221 / 222\end{array}$ & hMSC-TERT $_{20}$ & $\begin{array}{l}\text { CEBPB } \\
\text { CDKN1B }\end{array}$ & $\downarrow$ Adipogenesis & {$[86]$} \\
\hline
\end{tabular}

miR-26

hAD-MSC

ADAM17

$\uparrow$ Adipogenesis

[90]

hAD-MSCs, human adipose tissue-derived mesenchymal stem cells; MEFs, mouse embryonic fibroblasts; Pre-ad, preadipocytes; TERT, telomerase reverse transcriptase.

upregulated after hormonal induction of adipogenesis and based on those data, they concluded that overexpression of miR-17-92 cluster, with hormonal induction, may play a role in the positive regulation of adipocyte differentiation through targeting the tumor suppressor $\mathrm{Rb} / \mathrm{p} 130$ gene, resulting in acceleration of adipogenic differentiation [43].

$\mathrm{Kim}$ et al. investigated the role of miR-21 in adipogenic differentiation of human adipose tissue-derived mesenchymal stem cells (hAD-MSC) and its potential targets [44]. Their data showed that miR-21 can positively regulate adipogenic differentiation of hAD-MSC by targeting transforming growth factorbeta 1 (TGF- $\beta 1$ ), which is known to inhibit adipogenesis in vitro and in vivo [45]. In another study, Kang et al. showed that 3T3L1 cells that were transfected with miR-21 showed higher level of adipogenic differentiation [46], these results were indicated by the morphological changes in miR-21-transfected adipocytes that expressed higher levels of adiponectin. However, their data showed that miR-21 may regulate adipogenic commitment of preadipocytes by directly targeting AP1 gene, activating protein-1, resulting in inducing adipocyte differentiation.

Wingless-type MMTV integration family (Wnts) has been shown to suppress adipocyte differentiation by blocking the expression of PPAR $\gamma$ and CEBPA, which are essential transcription factors in adipogenesis [47]. These data were supported by different studies that were conducted to explore the role of different miRNAs in regulating adipogenesis via modulation of the Wnt pathway $[48,49]$. Kennell et al. first studied miRNA-8 in drosophila Kc167 cells and revealed that Wnt signaling pathway is regulated by miRNA-8 at different levels via inhibition of transcription factor (TCF) protein expression and direct targeting of wntless (wls) and CG32767 genes, which positively regulate Wnt signaling pathway, based on these data, they concluded that mammalian homologues of miRNA-8, miR-200c/141, and miR-200b/200a/429 clusters have a potential role in regulating adipocyte differentiation in ST2 marrow stromal cells [49]. Stable expression of miR-200c/141 and/or miR-200b/ $200 \mathrm{a} / 429$ clusters induced the differentiation of those cells into adipocytes, which was indicated by the elevated levels of fatty acid-binding protein 4 (FABP4), and an increase in lipid accumulation. In a similar manner, Qin et al. performed miRNA expression profiling during adipocyte differentiation and identified 18 miRNAs, including miR-210, miR-148a, miR-194, and miR-322, which could promote adipocyte differentiation via inhibition of Wnt signaling [48]. Overexpression of miR-210 in 3T3-L1 cells resulted in enlarged cells, with distinctive lipid droplets, while its inhibition led to diminished adipogenesis. The authors identified Tcf712, T-cell-specific transcription factor 7 like 2, a member of LEF/TCF family, which plays a role in triggering the downstream responsive genes of Wnt signaling [50], as bona fide target for miR-210.

Leukemia inhibitory factor (LIF) is an inflammatory cytokine that plays a significant role in regulating multiple biological activities such as cell survival, proliferation, and cell differentiation [51]. It was shown that LIF expression declines, in association with decreased differentiation plasticity of hMSCs [52-54]. Oskowitz et al. identified two miRNAs, miR-199 and miR-346, which can synergistically function by targeting LIF during hMSC differentiation, resulting in enhanced adipocyte and osteoblast differentiation [55].

Kruppel-like factor 5 (KLF5), a transcription factor, which function as signaling modulator for various cellular processes including cell proliferation, cell cycle, migration, 
apoptosis, and cell differentiation [56], was recently investigated as potential target for miR-448 [57]. The authors demonstrated that serotonin (5-HT) is a novel autocrine/ paracrine regulator of adipocytic cell differentiation [57]. Interestingly, the authors found miR-448, which is located in the fourth intron of 5-HT(2C)R, to suppress adipocyte differentiation by targeting KLF5 in the 3T3-L1 model.

\section{microRNAs targeting osteoblast-related genes}

Runt-related transcription factor 2 (RUNX2) is a master transcription factor known to regulate osteoblast and chondrocyte differentiation [58,59]. In undifferentiated cells, RUNX2 and PPAR $\gamma$ are expressed at low level to sustain differentiation potential of MSC [6,60]. It has been shown that reduction in the level of RUNX2 in chondrocytes enhanced their adipogenic commitment [61], while deficiency in PPAR $\gamma$ stimulates osteogenesis and enhanced bone formation [62]. Thus, Huang et al. intended to study whether RUNX2 regulation by miR-204/211 has an effect on adipogenic differentiation [63]. Many adipogenic genes such as AP2, adipsin, and PPAR $\gamma$ were found to be upregulated when miR-204 was overexpressed in ST2 cells, whereas upregulation of RUNX2 was observed in miR-204-spongetransfected cells. As a result, it has been revealed that miR-204 can positively regulate adipogenic commitment, probably through downregulation of RUNX2. In an independent study, Hamam et al. performed global microRNA and mRNA expression profiling during adipocytic differentiation of human bone marrow-derived MSCs (hBM-MSCs). While several differentially expressed miRNAs were identified in that study, the authors reported proadipogenic function for miR-320 family in hBM-MSCs via targeting multiple genes involved in cell differentiation and cell cycle regulation. The author subsequently validated RUNX2 as bona fide target for miR-320 family using the luciferase reporter system [64]. Zaragosi et al. reported miR-642-3p as a highly adipospecific miRNA, and additionally studied the involvement of miR-30 family in the regulation of adipogenesis in hADMSC [65]. Their data showed that during adipogenesis, miR642a-3p, miR-378, miR-30a, miR-30b, miR-30c, miR-30d, miR-30e, and miR-193b were strongly upregulated. In addition, a direct link between miR-30a and miR-30d and adipogenesis by targeting the activity of the transcription factor RUNX2, resulted in enhancing adipogenesis. RUNX2 has also been studied as a target gene for miRNAs involved in the regulation of adipogenesis in hMSCs derived from bone marrow, subcutaneous adipose tissue, and from articular cartilage [66]. Tome et al. reported that all MSC populations were found to express higher levels of miR-335 compared with dermal fibroblasts, and in addition, BM-MSCs showed the highest level of miR-335 expression among all examined MSC populations. Hence, miR-335 was reported to negatively regulate both adipogenic and osteogenic differentiation of hMSCs, as indicated by the reduction in PPAR $\gamma$ and osteopontin, respectively. The authors' data revealed RUNX2 as one target for miR-355, through direct binding to its $3^{\prime}$ untranslated region (UTR) and reduced level of RUNX2 protein after miR-355 overexpression.

Balancing between adipogenic and osteogenic differentiation in MSC, Zhang et al., demonstrated a role for miR637 in maintaining the balance between these two lineages by targeting Osterix (Osx) mRNA [67]. Osx, a zinc fingercontaining transcription factor, which plays significant role in bone and osteoblast formation and its transcription could be induced by bone morphogenetic protein 2 (BMP2) in hMSCs [68-71]. However, their data showed that Osterix is a direct target for miR-637 and its inhibition can positively regulate adipocyte differentiation, which was indicated by the elevated levels of PPAR $\gamma, \mathrm{C} / \mathrm{EBP} \alpha$, and SREBP-1c in de novo adipose tissue. Furthermore, the authors went to explore the effect of miR-637 on adipogenic differentiation in vivo using a de novo adipogenic mouse model. The authors noticed remarkable enhancement in adipose tissue formation after injection of Lv-miR-637-transduced hMSCs. Interestingly, the osteogenic differentiation potential of LvmiR-637-transduced cells was apparently diminished, which was associated with lower alkaline phosphatase activity.

\section{microRNAs targeting adipocyte-related genes}

Recently, miR-146b was studied for its role in regulating adipocytic differentiation [72], miR-146b was also revealed to be a positive regulator of adipogenesis in 3T3-L cells, and this effect was first indicated by the positive correlation between the expression level of this miRNA and adipose tissue volume in obese mice. miR-146b was reported to positively regulate adipogenic differentiation by targeting Sirtuin 1 (SIRT1) gene, which has been found to inhibit $\operatorname{PPAR} \gamma$ and stimulates lipolysis, resulting in delaying adipogenic commitment of 3T3-L1 cells and reducing fat production [73]. Additionally, miR-27 family was shown to play a role in adipogenic regulation by directly targeting adipogenic regulatory genes [74]. PPAR $\gamma$ and $\mathrm{C} / \mathrm{EBP} \alpha$ were reported to be key regulators of adipogenic differentiation and targeted by miR-27b, which suppresses their expression and negatively affect the adipogenic commitment in hADMSC cells, delaying the accumulation of triglyceride to late stages in these cells [75]. Moreover, and in a similar manner, Kim et al. demonstrated that miR-27a, another member of the miR-27 family, negatively regulated adipogenesis [76]. Their data showed that miR-27a was downregulated in mature adipocytes in the fraction of high-fat diet-fed obese mice. Their data showed that during adipocyte differentiation, overexpression of miR-27a in 3T3-L1 cells resulted in reduction of lipid accumulation, downregulation in PPAR $\gamma$ levels and reduced protein level of adiponectin. Moreover, they revealed that miR-27a overexpression represses many adipogenic marker genes such as adipocyte lipid-binding protein 2 (AP2), which is also known as FABP4, adiponectin, CD36, and lipoprotein lipase (LPL). Collectively, these results implied that miR-27a can target PPAR $\gamma$ directly, resulting in repression of adipogenesis suggesting that downregulation of miR-27a might be relevant to adipose tissue dysregulation in obesity.

In another study, PPAR $\gamma$ was also found to be targeted by miR-130 in both human and mouse preadipocytes, and was revealed to bind to both PPAR $\gamma$ mRNA coding and its 3' UTR [77]. In the same study, the authors reported lower levels of miR-130 in obese compared to lean women, which was linked to increased levels of PPAR $\gamma$ among relatively young and healthy populations. These lower expression levels of miR-130 in obese individuals could possibly reflect a reduced numbers of preadipocytes due to their conversion 
into mature adipocytes in the adipocyte pool. $\mathrm{C} / \mathrm{EBP} \alpha$ was found to be targeted by miR-31 in MSCs at both the transcriptional and translational levels, resulting in negative regulation of adipocyte differentiation [78]. The authors also revealed proadipogenic role for miR-24, via enhanced BMP2induced commitment to adipocytes. On the other hand, a study conducted by Yang et al. on hAD-MSCs revealed that miR-138 overexpression in these cells suppress the expression of PPAR $\gamma$ and $\mathrm{C} / \mathrm{EBP} \alpha$, and other adipocyte differentiation markers, such as FABP4 and lipoprotein 4, coupled with reduction in the accumulation of lipid droplets [79]. Furthermore, the adenovirus early region 1-A-like inhibitor of differentiation (EID-1) was predicted to be targeted by miR138 , which was previously reported to be involved in adipogenesis by promoting small heterodimer partner, an endogenous enhancer of PPAR $\gamma$, and TGF- $\beta$ signaling pathways. The authors succeeded to find a link between miR-138 and EID-1 gene and reveal that miR-138 can negatively regulate adipogenesis by the inhibition of EID-1 gene [80-82].

Concordant with previous studies implicating miR-103 and miR-107 in adipogenesis [83], Li et al. linked miR-103 to brain development, adipogenesis, lipid metabolism, immunity, and hematopoiesis [84]. Trajkovski et al. have also examined the effect of miR-103 and miR-107 during adipocyte differentiation of isolated stromal-vascular cells from visceral and subcutaneous fat [85]. Their data revealed increased number of adipocyte when miR-103 was inactivated, while overexpression of miR-107 resulted in reduced adipogenesis, which implicated miR-103 and miR107 in the negative regulation of adipocyte differentiation, via modulation of caveolin-1. Skarn et al. identified 12 miRNAs that were differentially expressed during adipocytic differentiation of hBM-MSC line (hMSC-TERT) and functionally validated miR-155, miR-221, and miR-222 as negative regulators of adipocytic differentiation of hMSCs via targeting CEBPB and CDKN1B [86].

\section{microRNAs targeting other pathways}

Karbiener et al. performed microarray on hAD-MSC and on mouse embryonic fibroblasts and found miR-30c to be upregulated during adipocytic differentiation [87]. Two genes, plasminogen activator inhibitor 1 (PAI-1) and activin receptor-like kinase 2 (ALK2), were identified as bona fide targets for miR-30c. Although these two targeted genes are so far not interconnected, the authors found that co-silencing, not single silencing of PAI-1 or ALK2 has a significant impact on adipogenesis as measured by elevated levels of triglycerides and lipid accumulation and the increased expression of adipogenic marker genes [PPAR $\gamma, \mathrm{C} / \mathrm{EBP} \alpha$, FABP4, fatty acid synthase (FASN), and glucose transporter type 4 (GLUT4)].

Gerin et al. investigated the role of miR-378/378* in adipocyte differentiation and metabolism, via knocking down Argonaute2 (Ago2), which plays a key role in miRNA processing, to study the potential role of different miRNAs in adipocyte differentiation and/or metabolism [88,89]. Although the authors observed no remarkable differences in adipogenesis between control and Ago2 knockdown samples of 3T3-L1 cells, incorporation of $\left[{ }^{14} \mathrm{C}\right]$ glucose or acetate into triacylglycerol showed reduced levels, which suggests that miRNAs may play a role in adipocyte metabolism. Moreover, they focused their studies to investigate the role of certain microRNAs in adipogenesis via screening differentially expressed microRNAs between preadipocytes and adipocytes in the 3T3-L1 and bone marrow-derived stroma (ST2) cell lines. miR-378/378* were highly induced during adipogenesis, and when they were overexpressed in ST2 MSC precursors, an increased level of lipid droplets, upregulation in several adipogenic markers [KLF15, FABP4, FASN, stearoyl-Coenzyme A desaturase 1 (SCD-1), and resistin], and increase in the incorporation of $\left[{ }^{14} \mathrm{C}\right] \mathrm{ac}-$ etate into triacylglycerol was observed. In contrast, knocking down miR-378 and/or miR-378* caused reduction in the accumulation of triacylglycerol. Interestingly, and in a traditional search for potential targets for specific miRNAs, Gerin et al. found that none of the predicted targets of miRNA-378 or $378^{*}$ were downregulated in response to these miRNAs. Unexpectedly, some of the suggested target genes exhibited an increase in reporter gene expression. In particular, $\mathrm{C} / \mathrm{EBP} \alpha$ and $\mathrm{C} / \mathrm{EBP} \beta$ activity on the GLUT4 promoter was increased in the presence of miRNA-378/ $378^{*}$, suggesting miRNAs might exert their effects in adipocytes through an atypical mechanism, such as transcriptional coactivation.

Recently, Karbiener et al. reported miR-26a family as a positive regulator of adipogenic differentiation in hADMSC [90]. Their data showed a significant increased in adipocytes formation assessed by oil red staining and high expression of adipogenic markers upon overexpression of

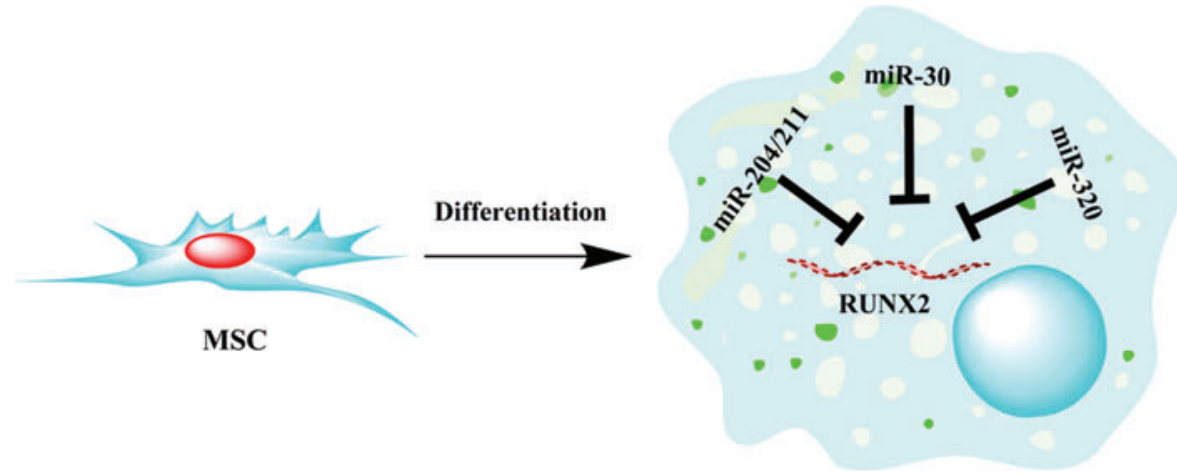

Adipocyte
FIG. 1. Regulation of runt-related transcription factor 2 (RUNX2) by miR-204/211, miR-30, and miR-320 family. During adipocytic differentiation of mesenchymal stem cells (MSCs), members of the miR-204/ 211, miR-30, and miR-320 family are upregulated, which subsequently repress RUNX2 and promote adipogenesis. Color images available online at www.liebertpub.com/scd 
miR-26a and miR-26b. Transcriptomatic analysis revealed enriched TGF- $\beta$ and Notch signaling pathways among miR26a-suppressed mRNA. Furthermore, miR-26a showed significant effect on the expression level of various genes involved in different cellular pathways, such as pyruvate metabolism, tricarboxylic acid (TCA) cycle, and fatty acid metabolism suggesting increased de novo synthesis of lipids combined with an increase level of triglyceride accumulation upon miR-26 at the early white stage. However, In their functional studies, knocking down of several mRNAs (SMURF2, ATPAF1, ADAM17, and PLOD2) showed a positive effect on adipogenic differentiation as indicated by lipid accumulation, however, induction of UCP1 was only observed upon knocking down of ADAM metallopeptidase domain 17 (ADAM17), which also was shown to be the most downregulated transcriptom by miR26a. Karbiener et al. revealed the direct miR-26-ADAM17 interaction indicating that ADAM17 is a direct target for miR-26 family with an antiadipogenic and antibrowning effect [90].

\section{Conclusion Remarks}

The role of miRNA-mediated post-transcriptional regulation in adipogenesis has been studied particularly to identify the schematic mechanism of microRNA and gene regulation of adipogenic differentiation of stem cells. Thus far, several microRNA families has been identified using high-throughput screen, computational and experimental approaches and were found to regulate adipogenesis by targeting key pathways involved in stem cell differentiation and proliferation. Of particular interest, we and others have identified RUNX2 to be a favorite hub for microRNAmediated gene silencing during adipogenesis. RUNX2 has been shown to be targeted by miR-204/211 and miR-30 families, and most recently we found RUNX2 to be highly targeted by miR-320 family during adipocytic differentiation of hMSCs (Fig. 1) [64]. The findings from miRNA investigations during adipogenesis suggest the potential utilization of miRNA mimics/inhibitors or sponge to treat bone diseases, metabolic disorders, and obesity. As proof of principle, several preclinical data have shown the feasibility of utilizing miRNA-based therapies in vivo in various disease models [17,91-93]. The only miRNA-based therapy in clinical trials thus far is miravirsen, which is a miR-122 inhibitor previously shown to reduce $\mathrm{HCV}$ viral load in a primate HCV disease model [93]. Santaris Pharma A/S has completed phase I and phase II clinical trials using this agent in healthy subject and patients with chronic hepatitis C infection (http://clinicaltrials.gov). Therefore, the translation of in vitro and preclinical findings in this field into clinical trials is just beginning to unfold. Determining biodistribution, specificity, pharmacokinetics, and safety have to be addressed before the successful utilization of miRNAdirected therapies in the clinic.

\section{Acknowledgment}

This work was supported by the National Science Technology and Innovation Plan (NSTIP) strategic technologies program, grant number (11-BIO-1941-02) in the Kingdom of Saudi Arabia.

\section{Author Disclosure Statement}

The authors declare no conflicts of interest.

\section{References}

1. Pittenger MF, AM Mackay, SC Beck, RK Jaiswal, R Douglas, JD Mosca, MA Moorman, DW Simonetti, S Craig and DR Marshak. (1999). Multilineage potential of adult human mesenchymal stem cells. Science 284:143-147.

2. Zuk PA, M Zhu, P Ashjian, DA De Ugarte, JI Huang, H Mizuno, ZC Alfonso, JK Fraser, P Benhaim and $\mathrm{MH} \mathrm{He}-$ drick. (2002). Human adipose tissue is a source of multipotent stem cells. Mol Biol Cell 13:4279-4295.

3. Erices A, P Conget and JJ Minguell. (2000). Mesenchymal progenitor cells in human umbilical cord blood. $\mathrm{Br} \mathrm{J}$ Haematol 109:235-242.

4. Vishnubalaji R, M Manikandan, M Al-Nbaheen, B Kadalmani, A Aldahmash and NM Alajez. (2012). In vitro differentiation of human skin-derived multipotent stromal cells into putative endothelial-like cells. BMC Dev Biol 12:7.

5. Wislet-Gendebien S, G Hans, P Leprince, JM Rigo, G Moonen and B Rogister. (2005). Plasticity of cultured mesenchymal stem cells: switch from nestin-positive to excitable neuron-like phenotype. Stem Cells 23:392-402.

6. Rosen ED and OA MacDougald. (2006). Adipocyte differentiation from the inside out. Nat Rev Mol Cell Biol 7:885-896.

7. Rosen ED, CJ Walkey, P Puigserver and BM Spiegelman. (2000). Transcriptional regulation of adipogenesis. Genes Dev 14:1293-1307.

8. Gimble JM, CE Robinson, X Wu and KA Kelly. (1996). The function of adipocytes in the bone marrow stroma: an update. Bone 19:421-428.

9. Baek D, J Villen, C Shin, FD Camargo, SP Gygi and DP Bartel. (2008). The impact of microRNAs on protein output. Nature 455:64-71.

10. Lim LP, NC Lau, P Garrett-Engele, A Grimson, JM Schelter, J Castle, DP Bartel, PS Linsley and JM Johnson. (2005). Microarray analysis shows that some microRNAs downregulate large numbers of target mRNAs. Nature 433:769-773.

11. Selbach M, B Schwanhausser, N Thierfelder, Z Fang, R Khanin and N Rajewsky. (2008). Widespread changes in protein synthesis induced by microRNAs. Nature 455:58-63.

12. Alajez NM, M Lenarduzzi, E Ito, AB Hui, W Shi, J Bruce, S Yue, SH Huang, W Xu, et al. (2011). MiR-218 suppresses nasopharyngeal cancer progression through downregulation of survivin and the SLIT2-ROBO1 pathway. Cancer Res 71:2381-2391.

13. Bushati N and SM Cohen. (2007). microRNA functions. Annu Rev Cell Dev Biol 23:175-205.

14. Calin GA and CM Croce. (2006). MicroRNA signatures in human cancers. Nat Rev Cancer 6:857-866.

15. Alajez NM, W Shi, AB Hui, J Bruce, M Lenarduzzi, E Ito, S Yue, B O'Sullivan and FF Liu. (2010). Enhancer of Zeste homolog 2 (EZH2) is overexpressed in recurrent nasopharyngeal carcinoma and is regulated by miR-26a, miR-101, and miR-98. Cell Death Dis 1:e85.

16. Alajez NM. (2011). Cancer stem cells. From characterization to therapeutic implications. Saudi Med J 32:1229-1234.

17. Eulalio A, M Mano, M Dal Ferro, L Zentilin, G Sinagra, S Zacchigna and M Giacca. (2012). Functional screening identifies miRNAs inducing cardiac regeneration. Nature 492:376-381. 
18. Quiat D and EN Olson. (2013). MicroRNAs in cardiovascular disease: from pathogenesis to prevention and treatment. J Clin Invest 123:11-18.

19. Cao L, EJ Lin, MC Cahill, C Wang, X Liu and MJ During. (2009). Molecular therapy of obesity and diabetes by a physiological autoregulatory approach. Nat Med 15:447-454.

20. Hilton C, MJ Neville and F Karpe. (2012). MicroRNAs in adipose tissue: their role in adipogenesis and obesity. Int $\mathrm{J}$ Obes (Lond) 37:325-332.

21. Dehwah MA, A Xu and Q Huang. (2012). MicroRNAs and type 2 diabetes/obesity. J Genet Genomics 39:11-18.

22. Krichevsky AM, KC Sonntag, O Isacson and KS Kosik. (2006). Specific microRNAs modulate embryonic stem cell-derived neurogenesis. Stem Cells 24:857-864.

23. Chen JF, EM Mandel, JM Thomson, Q Wu, TE Callis, SM Hammond, FL Conlon and DZ Wang. (2006). The role of microRNA-1 and microRNA-133 in skeletal muscle proliferation and differentiation. Nat Genet 38:228-233.

24. Zhao Y, E Samal and D Srivastava. (2005). Serum response factor regulates a muscle-specific microRNA that targets Hand2 during cardiogenesis. Nature 436:214-220.

25. Pedersen I and M David. (2008). MicroRNAs in the immune response. Cytokine 43:391-394.

26. Kloosterman WP, AK Lagendijk, RF Ketting, JD Moulton and RH Plasterk. (2007). Targeted inhibition of miRNA maturation with morpholinos reveals a role for miR-375 in pancreatic islet development. PLoS Biol 5:e203.

27. Tay YM, WL Tam, YS Ang, PM Gaughwin, H Yang, W Wang, R Liu, J George, HH Ng, et al. (2008). MicroRNA134 modulates the differentiation of mouse embryonic stem cells, where it causes post-transcriptional attenuation of Nanog and LRH1. Stem Cells 26:17-29.

28. Taipaleenmaki H, L Bjerre Hokland, L Chen, S Kauppinen and M Kassem. (2012). Mechanisms in endocrinology: micro-RNAs: targets for enhancing osteoblast differentiation and bone formation. Eur J Endocrinol 166:359-371.

29. Lian JB, GS Stein, AJ van Wijnen, JL Stein, MQ Hassan, T Gaur and Y Zhang. (2012). MicroRNA control of bone formation and homeostasis. Nat Rev Endocrinol 8:212-227.

30. Gregoire FM, CM Smas and HS Sul. (1998). Understanding adipocyte differentiation. Physiol Rev 78:783-809.

31. Barak Y, MC Nelson, ES Ong, YZ Jones, P Ruiz-Lozano, KR Chien, A Koder and RM Evans. (1999). PPAR gamma is required for placental, cardiac, and adipose tissue development. Mol Cell 4:585-595.

32. Rosen ED, P Sarraf, AE Troy, G Bradwin, K Moore, DS Milstone, BM Spiegelman and RM Mortensen. (1999). PPAR gamma is required for the differentiation of adipose tissue in vivo and in vitro. Mol Cell 4:611-617.

33. Tontonoz P, JB Kim, RA Graves and BM Spiegelman. (1993). ADD1: a novel helix-loop-helix transcription factor associated with adipocyte determination and differentiation. Mol Cell Biol 13:4753-4759.

34. Yokoyama C, X Wang, MR Briggs, A Admon, J Wu, X Hua, JL Goldstein and MS Brown. (1993). SREBP-1, a basic-helix-loop-helix-leucine zipper protein that controls transcription of the low density lipoprotein receptor gene. Cell 75:187-197.

35. Chen Z, JI Torrens, A Anand, BM Spiegelman and JM Friedman. (2005). Krox20 stimulates adipogenesis via C/ EBPbeta-dependent and -independent mechanisms. Cell Metab 1:93-106.

36. Birsoy K, Z Chen and J Friedman. (2008). Transcriptional regulation of adipogenesis by KLF4. Cell Metab 7:339-347.
37. Nanbu-Wakao R, Y Morikawa, I Matsumura, Y Masuho, MA Muramatsu, E Senba and H Wakao. (2002). Stimulation of 3T3-L1 adipogenesis by signal transducer and activator of transcription 5. Mol Endocrinol 16:1565-1576.

38. Ortega FJ, JM Moreno-Navarrete, G Pardo, M Sabater, M Hummel, A Ferrer, JI Rodriguez-Hermosa, B Ruiz, W Ricart, B Peral and JM Fernandez-Real. (2010). MiRNA expression profile of human subcutaneous adipose and during adipocyte differentiation. PLoS One 5:e9022.

39. Esau C, X Kang, E Peralta, E Hanson, EG Marcusson, LV Ravichandran, Y Sun, S Koo, RJ Perera, et al. (2004). MicroRNA-143 regulates adipocyte differentiation. J Biol Chem 279:52361-52365.

40. Kim SW, AM Muise, PJ Lyons and HS Ro. (2001). Regulation of adipogenesis by a transcriptional repressor that modulates MAPK activation. J Biol Chem 276:10199_ 10206.

41. Kato Y, RI Tapping, S Huang, MH Watson, RJ Ulevitch and JD Lee. (1998). Bmk1/Erk5 is required for cell proliferation induced by epidermal growth factor. Nature 395:713-716.

42. Ling HY, GB Wen, SD Feng, QH Tuo, HS Ou, CH Yao, BY Zhu, ZP Gao, L Zhang and DF Liao. (2011). MicroRNA-375 promotes 3T3-L1 adipocyte differentiation through modulation of extracellular signal-regulated kinase signalling. Clin Exp Pharmacol Physiol 38:239-246.

43. Wang Q, YC Li, J Wang, J Kong, Y Qi, RJ Quigg and X Li. (2008). miR-17-92 cluster accelerates adipocyte differentiation by negatively regulating tumor-suppressor $\mathrm{Rb} 2 /$ p130. Proc Natl Acad Sci U S A 105:2889-2894.

44. Kim YJ, SJ Hwang, YC Bae and JS Jung. (2009). MiR-21 regulates adipogenic differentiation through the modulation of TGF-beta signaling in mesenchymal stem cells derived from human adipose tissue. Stem Cells 27:3093-3102.

45. Ignotz RA and J Massague. (1985). Type beta transforming growth factor controls the adipogenic differentiation of 3T3 fibroblasts. Proc Natl Acad Sci U S A 82:8530-8534.

46. Kang M, LM Yan, WY Zhang, YM Li, AZ Tang and HS Ou. (2013). Role of microRNA-21 in regulating 3T3-L1 adipocyte differentiation and adiponectin expression. Mol Biol Rep 40:5027-5034.

47. Ross SE, N Hemati, KA Longo, CN Bennett, PC Lucas, RL Erickson and OA MacDougald. (2000). Inhibition of adipogenesis by Wnt signaling. Science 289:950-953.

48. Qin L, Y Chen, Y Niu, W Chen, Q Wang, S Xiao, A Li, Y Xie, J Li, et al. (2010). A deep investigation into the adipogenesis mechanism: profile of microRNAs regulating adipogenesis by modulating the canonical Wnt/beta-catenin signaling pathway. BMC Genomics 11:320.

49. Kennell JA, I Gerin, OA MacDougald and KM Cadigan. (2008). The microRNA miR-8 is a conserved negative regulator of Wnt signaling. Proc Natl Acad Sci U S A 105:15417-15422.

50. Koslowski MJ, I Kubler, M Chamaillard, E Schaeffeler, W Reinisch, G Wang, J Beisner, A Teml, L Peyrin-Biroulet, et al. (2009). Genetic variants of Wnt transcription factor TCF-4 (TCF7L2) putative promoter region are associated with small intestinal Crohn's disease. PLoS One 4:e4496.

51. Heinrich PC, I Behrmann, S Haan, HM Hermanns, G Muller-Newen and F Schaper. (2003). Principles of interleukin (IL)-6-type cytokine signalling and its regulation. Biochem J 374:1-20.

52. Kim DH, KH Yoo, KS Choi, J Choi, SY Choi, SE Yang, YS Yang, HJ Im, KH Kim, et al. (2005). Gene expression 
profile of cytokine and growth factor during differentiation of bone marrow-derived mesenchymal stem cell. Cytokine 31:119-126.

53. Majumdar MK, MA Thiede, SE Haynesworth, SP Bruder and SL Gerson. (2000). Human marrow-derived mesenchymal stem cells (MSCs) express hematopoietic cytokines and support long-term hematopoiesis when differentiated toward stromal and osteogenic lineages. J Hematother Stem Cell Res 9:841-848.

54. Vacanti V, E Kong, G Suzuki, K Sato, JM Canty and T Lee. (2005). Phenotypic changes of adult porcine mesenchymal stem cells induced by prolonged passaging in culture. J Cell Physiol 205:194-201.

55. Oskowitz AZ, J Lu, P Penfornis, J Ylostalo, J McBride, EK Flemington, DJ Prockop and R Pochampally. (2008). Human multipotent stromal cells from bone marrow and microRNA: regulation of differentiation and leukemia inhibitory factor expression. Proc Natl Acad Sci U S A 105:18372-18377.

56. Dong JT and C Chen. (2009). Essential role of KLF5 transcription factor in cell proliferation and differentiation and its implications for human diseases. Cell Mol Life Sci 66:2691-2706.

57. Kinoshita M, K Ono, T Horie, K Nagao, H Nishi, Y Kuwabara, $\mathrm{R}$ Takanabe-Mori, $\mathrm{K}$ Hasegawa, $\mathrm{T}$ Kita and $\mathrm{T}$ Kimura. (2010). Regulation of adipocyte differentiation by activation of serotonin (5-HT) receptors 5-HT2AR and 5HT2CR and involvement of microRNA-448-mediated repression of KLF5. Mol Endocrinol 24:1978-1987.

58. Komori T, H Yagi, S Nomura, A Yamaguchi, K Sasaki, K Deguchi, Y Shimizu, RT Bronson, YH Gao, et al. (1997). Targeted disruption of Cbfa1 results in a complete lack of bone formation owing to maturational arrest of osteoblasts. Cell 89:755-764.

59. Yoshida CA, H Yamamoto, T Fujita, T Furuichi, K Ito, K Inoue, K Yamana, A Zanma, K Takada, Y Ito and T Komori. (2004). Runx2 and Runx3 are essential for chondrocyte maturation, and Runx 2 regulates limb growth through induction of Indian hedgehog. Genes Dev 18:952-963.

60. Bennett CN, KA Longo, WS Wright, LJ Suva, TF Lane, KD Hankenson and OA MacDougald. (2005). Regulation of osteoblastogenesis and bone mass by Wnt10b. Proc Natl Acad Sci U S A 102:3324-3329.

61. Enomoto H, T Furuichi, A Zanma, K Yamana, C Yoshida, S Sumitani, H Yamamoto, M Enomoto-Iwamoto, M Iwamoto and T Komori. (2004). Runx2 deficiency in chondrocytes causes adipogenic changes in vitro. J Cell Sci 117:417-425.

62. Akune T, S Ohba, S Kamekura, M Yamaguchi, UI Chung, N Kubota, Y Terauchi, Y Harada, Y Azuma, et al. (2004). PPARgamma insufficiency enhances osteogenesis through osteoblast formation from bone marrow progenitors. J Clin Invest 113:846-855.

63. Huang J, L Zhao, L Xing and D Chen. (2010). MicroRNA204 regulates Runx2 protein expression and mesenchymal progenitor cell differentiation. Stem Cells 28:357-364.

64. Hamam D, D Ali, R Vishnubalaji, M Al-Nbaheen, A Aldahmash, M Kassem and NM Alajez. (2014). microRNA320/RUNX2 axis regulates adipocytic differentiation of human mesenchymal (Skeletal) stem cells. Cell Death Dis 5:e1499.

65. Zaragosi LE, B Wdziekonski, KL Brigand, P Villageois, B Mari, R Waldmann, C Dani and P Barbry. (2011). Small RNA sequencing reveals miR-642a-3p as a novel adipo- cyte-specific microRNA and miR-30 as a key regulator of human adipogenesis. Genome Biol 12:R64.

66. Tome M, P Lopez-Romero, C Albo, JC Sepulveda, B Fernandez-Gutierrez, A Dopazo, A Bernad and MA Gonzalez. (2011). miR-335 orchestrates cell proliferation, migration and differentiation in human mesenchymal stem cells. Cell Death Differ 18:985-995.

67. Zhang JF, WM Fu, ML He, H Wang, WM Wang, SC Yu, XW Bian, J Zhou, MC Lin, et al. (2011). MiR-637 maintains the balance between adipocytes and osteoblasts by directly targeting Osterix. Mol Biol Cell 22:3955-3961.

68. Nakashima K, X Zhou, G Kunkel, Z Zhang, JM Deng, RR Behringer and B de Crombrugghe. (2002). The novel zinc finger-containing transcription factor osterix is required for osteoblast differentiation and bone formation. Cell 108:17-29.

69. Celil AB, JO Hollinger and PG Campbell. (2005). Osx transcriptional regulation is mediated by additional pathways to BMP2/Smad signaling. J Cell Biochem 95:518-528.

70. Lee MH, TG Kwon, HS Park, JM Wozney and HM Ryoo. (2003). BMP-2-induced Osterix expression is mediated by Dlx 5 but is independent of Runx2. Biochem Biophys Res Commun 309:689-694.

71. Ryoo HM, MH Lee and YJ Kim. (2006). Critical molecular switches involved in BMP-2-induced osteogenic differentiation of mesenchymal cells. Gene 366:51-57.

72. Ahn J, H Lee, CH Jung, TI Jeon and TY Ha. (2013). MicroRNA-146b promotes adipogenesis by suppressing the SIRT1-FOXO1 cascade. EMBO Mol Med 5:1602-1612.

73. Picard F, M Kurtev, N Chung, A Topark-Ngarm, T Senawong, R Machado De Oliveira, M Leid, MW McBurney and L Guarente. (2004). Sirt1 promotes fat mobilization in white adipocytes by repressing PPAR-gamma. Nature 429:771-776.

74. Lin Q, Z Gao, RM Alarcon, J Ye and Z Yun. (2009). A role of miR-27 in the regulation of adipogenesis. FEBS $\mathrm{J}$ 276:2348-2358.

75. Karbiener M, C Fischer, S Nowitsch, P Opriessnig, C Papak, G Ailhaud, C Dani, EZ Amri and M Scheideler. (2009). microRNA miR-27b impairs human adipocyte differentiation and targets PPARgamma. Biochem Biophys Res Commun 390:247-251.

76. Kim SY, AY Kim, HW Lee, YH Son, GY Lee, JW Lee, YS Lee and JB Kim. (2010). miR-27a is a negative regulator of adipocyte differentiation via suppressing PPARgamma expression. Biochem Biophys Res Commun 392:323-328.

77. Lee EK, MJ Lee, K Abdelmohsen, W Kim, MM Kim, S Srikantan, JL Martindale, ER Hutchison, HH Kim, et al. (2011). miR-130 suppresses adipogenesis by inhibiting peroxisome proliferator-activated receptor gamma expression. Mol Cell Biol 31:626-638.

78. Sun F, J Wang, Q Pan, Y Yu, Y Zhang, Y Wan, X Li and A Hong. (2009). Characterization of function and regulation of miR-24-1 and miR-31. Biochem Biophys Res Commun 380:660-665.

79. Yang Z, C Bian, H Zhou, S Huang, S Wang, L Liao and RC Zhao. (2011). MicroRNA hsa-miR-138 inhibits adipogenic differentiation of human adipose tissue-derived mesenchymal stem cells through adenovirus EID-1. Stem Cells Dev 20:259-267.

80. Bavner A, L Johansson, G Toresson, JA Gustafsson and E Treuter. (2002). A transcriptional inhibitor targeted by the atypical orphan nuclear receptor SHP. EMBO Rep 3:478-484.

81. Macchiarulo A, G Rizzo, G Costantino, S Fiorucci and R Pellicciari. (2006). Unveiling hidden features of orphan 
nuclear receptors: the case of the small heterodimer partner (SHP). J Mol Graph Model 24:362-372.

82. Nishizawa H, K Yamagata, I Shimomura, M Takahashi, H Kuriyama, K Kishida, K Hotta, H Nagaretani, N Maeda, et al. (2002). Small heterodimer partner, an orphan nuclear receptor, augments peroxisome proliferator-activated receptor gamma transactivation. J Biol Chem 277:1586-1592.

83. Bengestrate L, S Virtue, M Campbell, A Vidal-Puig, D Hadaschik, P Hahn and W Bielke. (2011). Genome-wide profiling of microRNAs in adipose mesenchymal stem cell differentiation and mouse models of obesity. PLoS One 6:e21305.

84. Li G, Z Wu, X Li, X Ning, Y Li and G Yang. (2011). Biological role of microRNA-103 based on expression profile and target genes analysis in pigs. Mol Biol Rep 38:4777-4786.

85. Trajkovski M, J Hausser, J Soutschek, B Bhat, A Akin, M Zavolan, MH Heim and M Stoffel. (2011). MicroRNAs 103 and 107 regulate insulin sensitivity. Nature 474:649-653.

86. Skarn M, HM Namlos, P Noordhuis, MY Wang, LA MezaZepeda and O Myklebost. (2012). Adipocyte differentiation of human bone marrow-derived stromal cells is modulated by microRNA-155, microRNA-221, and microRNA-222. Stem Cells Dev 21:873-883.

87. Karbiener M, C Neuhold, P Opriessnig, A Prokesch, JG Bogner-Strauss and M Scheideler. (2011). MicroRNA-30c promotes human adipocyte differentiation and co-represses PAI-1 and ALK2. RNA Biol 8:850-860.

88. Gerin I, GT Bommer, CS McCoin, KM Sousa, V Krishnan and OA MacDougald. (2010). Roles for miRNA-378/378* in adipocyte gene expression and lipogenesis. Am J Physiol Endocrinol Metab 299:E198-E206.

89. Diederichs S and DA Haber. (2007). Dual role for argonautes in microRNA processing and posttranscriptional regulation of microRNA expression. Cell 131:1097-1108.
90. Karbiener M, DF Pisani, A Frontini, LM Oberreiter, E Lang, A Vegiopoulos, K Mossenbock, GA Bernhardt, T Mayr, et al. (2014). MicroRNA-26 family is required for human adipogenesis and drives characteristics of brown adipocytes. Stem Cells 32:1578-1590.

91. Obad S, CO dos Santos, A Petri, M Heidenblad, O Broom, C Ruse, C Fu, M Lindow, J Stenvang, et al. (2011). Silencing of microRNA families by seed-targeting tiny LNAs. Nat Genet 43:371-378.

92. Babar IA, CJ Cheng, CJ Booth, X Liang, JB Weidhaas, WM Saltzman and FJ Slack. (2012). Nanoparticle-based therapy in an in vivo microRNA-155 (miR-155)-dependent mouse model of lymphoma. Proc Natl Acad Sci U S A 109:E1695-E704.

93. Lanford RE, ES Hildebrandt-Eriksen, A Petri, R Persson, M Lindow, ME Munk, S Kauppinen and H Orum. (2010). Therapeutic silencing of microRNA-122 in primates with chronic hepatitis C virus infection. Science 327:198-201.

Address correspondence to: Dr. Nehad M. Alajez. Stem Cell Unit Department of Anatomy College of Medicine King Saud University Riyadh 11461 Kingdom of Saudi Arabia

E-mail: nalajez@ksu.edu.sa

Received for publication July 6, 2014 Accepted after revision November 10, 2014 Prepublished on Liebert Instant Online November 18, 2014 